OPEN ACCESS

Edited by:

Zezhi Li,

Shanghai JiaoTong University, China

Reviewed by:

Qingshan Zhang,

Université Claude Bernard Lyon

1, France

Shuwei Xie,

University of Nebraska Medical

Center, United States

${ }^{*}$ Correspondence:

Jibing Wang

benwangking@126.com

Ming Yang

yangm_swu@163.com

Jindong Chang

changlai@163.com

Specialty section:

This article was submitted to

Aging Psychiatry,

a section of the journal

Frontiers in Psychiatry

Received: 23 May 2021 Accepted: 28 June 2021 Published: 20 July 2021

Citation:

Yong L, Liu L, Ding T, Yang G, Su H, Wang J, Yang M and Chang J (2021) Evidence of Effect of Aerobic Exercise on Cognitive Intervention in Older Adults With Mild Cognitive Impairment.

Front. Psychiatry 12:713671. doi: 10.3389/fpsyt.2021.713671

\section{Evidence of Effect of Aerobic Exercise on Cognitive Intervention in Older Adults With Mild Cognitive Impairment}

\author{
Liming Yong ${ }^{1,2}$, Lei Liu ${ }^{3}$, Ting Ding ${ }^{3}$, Gao Yang ${ }^{1}$, Haibing Su ${ }^{1}$, Jibing Wang ${ }^{4 *}$, \\ Ming Yang ${ }^{1,2 *}$ and Jindong Chang ${ }^{1,2 *}$
}

${ }^{1}$ School of Physical Education, Southwest University, Chongqing, China, ${ }^{2}$ Institute of Motor Quotient, Southwest University, Chongqing, China, ${ }^{3}$ Qingdao Mental Health Center, Qingdao University, Qingdao, China, ${ }^{4}$ International College of Football, Tongji University, Shanghai, China

This study aimed to evaluate the effectiveness of aerobic exercise as a cognitive intervention for older adults with mild cognitive impairment (MCl). The PubMed, EMBASE (Ovid), Cochrane Library, Web of Science, and Medline databases were searched from their inception until 30 April 2021. Randomized controlled trials (RCTs) examining the effects of aerobic exercise on global cognitive function in older adults with $\mathrm{MCl}$ were included. Ten eligible trials with acceptable methodological quality were identified. The meta-analysis results showed that aerobic exercise significantly improved the MMSE $\left(N=956, M D=0.60,95 \% \mathrm{Cl}: 0.28-0.92, p=0.0003, R^{2}=31 \%\right.$, fixed effects model) and MoCA scores ( $N=398, M D=1.67,95 \%$ Cl. 1.18-2.15, $p<0.0001, R^{2}=37 \%$, fixed-effects model) and overall cognitive performance in patients with $\mathrm{MCl}$. The results of this study suggest that participation in regular aerobic exercise can improve cognitive function in older adults with $\mathrm{MCl}$. These findings should be used with caution considering the limitations of the study.

Keywords: aerobic exercise, mild cognitive impairment, RCTs, systematic review, meta-analysis

\section{INTRODUCTION}

Mild cognitive impairment (MCI) is a typical transitional stage between the normal aging process and the onset of dementia. Mild cognitive impairment includes a group of cognitive impairment conditions presenting in the early stages of dementia (1). According to recent studies involving people over 60 years of age, the prevalence of $\mathrm{MCI}$ is about $15 \%(2,3)$, while another cohort study in Beijing, China showed that a prevalence of MCI in older adults of $16.6 \%$ (4). In addition, domestic studies have reported conversion rates from MCI to dementia and Alzheimer's disease (AD) of 34 and $28 \%$, respectively $(2,3)$. There is no positive evidence to support the use of pharmacological interventions to attenuate cognitive decline in MCI patients (5-8). Instead, risk reduction factors (9) and participation in physical activity are widely considered to be effective non-pharmacological interventions. Although studies have investigated the effects of non-pharmacological interventions including diet (10), social relationships $(7,11)$, and cognitive training $(12-14)$, the advantages of exercise/physical activity are unknown.

A growing number of studies are suggesting that physical activity/exercise may improve cognitive function. However, a meta-analysis of 14 randomized controlled trials (RCTs) reported 
that there is no significant evidence that physical activity/exercise improves cognitive function in patients with MCI (15). However, in an intervention involving individuals with $\mathrm{MCI}$, the Hamer prospective study review demonstrated an inverse relationship between physical activity/exercise and the risk of cognitive decline in healthy older adults (14). This evidence is also supported by the results of cross-sectional studies, longitudinal observational studies, and prospective intervention trials (16-21).

Several studies have investigated with beneficial effects of aerobic exercise in older adults with MCI in order to better understand the effects of exercise and how these change depending on the type of exercise performed $(8,15,16)$. Although 11 previous aerobic exercise meta-analysis studies found favorable effects on overall cognitive performance and memory in older adults, the effects of beneficial effects on older adults with MCI varied widely depending on the type, frequency, and duration of aerobic exercise performed. Furthermore, it has been suggested that due to differences in measurement instruments used, results regarding the effects of aerobic exercise on cognitive interventions in older adults with MCI have not been uniform (15). Therefore, the purpose of this systematic evaluation and meta-analysis was to investigate the effects of exercise interventions on older adults with MCI based on the measurement tools used and the type of exercise performed and to evaluate the exercise intervention modality recommended in a RCT.

\section{METHODS}

\section{Search Strategy}

This study used the Preferred Reporting Items for Systematic Reviews and Meta-Analyses guidelines (22). We searched for relevant studies written in English in PubMed, EMBASE (Ovid), Cochrane Library, Web of Science, Medline, and other databases for aerobics-related subject terms (e.g., aerobic exercise, aerobic dance, Qigong, Tai Chi, Yoga, physical activity) and cognitive impairment-related subject headings (e.g., MCI, memory loss, cognitive impairment). All search terms were grouped together as much as possible to find all relevant studies. In addition, previously cited studies were manually added if they met the inclusion criteria. Supplementary Materials used for the search strategy of the articles were available online (See Appendix 1. The literature was searched from its inception to April 30, 2021).

\section{Inclusion and Exclusion Criteria}

The following inclusion criteria had to be met for exercise intervention trials to be included in this review: (1) Study design: RCTs, including those published by peer review or peerreviewed journals in print; (2) Participants: older adults (60 years and older) with MCI that met the existing diagnostic criteria. Those with cognitive impairment or other neurological impairments due to $\mathrm{AD}$ or dementia were excluded from the study; (3) Intervention: the experimental group performed different types of aerobic exercise (e.g., yoga, tai chi, running, walking, dancing, etc.) for at least 8 weeks and exercised at least once per week; (4) Control: the control group did not perform specific exercise interventions, i.e., the control group only maintained their usual physical activity or performed sham exercises (e.g., stretching and balancing, exercise education, etc.); (5) Outcome: the subjects' overall cognitive abilities or specific cognitive domain abilities such as memory, attention, etc. were measured by any of the Mini-Mental State Examination (MMSE) and Montreal Cognitive Assessment (MoCA) measurement instruments. Studies without available data were excluded.

\section{Assessing the Risk of Bias}

The Cochrane Risk of Bias tool was used to assess the risk of bias in the included trials (23). In addition, selection bias, performance bias, detection bias, attrition bias, reporting bias, and other types of bias were assessed, and each study was categorized as high, low, or unclear based on the degree of bias present. This work was done independently by two evaluators (LY and GY). Disagreements between the two reviewers were resolved through discussion with the two corresponding authors (JW and JC).

\section{Statistical Analysis}

RevMan version 5.4.1 software (Cochrane) was used for this meta-analysis of the study. The mean difference (MD) or standardized difference (SMD) statistic was used to calculate the combined effect size, and the corresponding 95\% CI was used to summarize the data. If the fit heterogeneity of the selected study data was small $\left(I^{2} \leq 50 \%, p>0.05\right)$, the analysis model was deemed to be a fixed-effects model. If the data heterogeneity of the selected studies was high $\left(I^{2}>50 \%, p\right.$ $<0.05)$, the analytical model was deemed to be a randomeffects model. However, when the level of heterogeneity between studies was high $\left(I^{2}>75 \%\right)$, the overall combined analysis was considered inappropriate due to reasons of heterogeneity, including the characteristics of the measurement instruments. Statistical heterogeneity in the included studies was assessed using the $\chi^{2}$-test and $I^{2}$-values, with $I^{2}>75 \%$ indicating a high degree of statistical heterogeneity (24).

\section{RESULTS}

\section{Study Identification}

Following a predetermined search strategy, 5,541 records were initially identified from four major electronic databases. Two reviewers (LY and GY) removed 5,487 irrelevant studies based on their abstracts and titles, leaving a total of 54 potential studies to be further assessed for eligibility. Following assessment, 10 studies were included in a systematic review and meta-analysis involving 1,364 MCI participants. Figure 1 shows the detailed process used to screen eligible studies.

\section{Characteristics of the Included Studies}

Table 1 presents the characteristics of each included study. A total of 10 RCTs involving 1,364 MCI participants (454 men and 910 women, mean age $73.0 \pm 6.72$ years) were included in the analysis. All studies were published between 2012 and 2021. The study countries and regions included China $(26,31,34)(n=$ $3)$, Hong Kong $(28,29)(n=2)$, Japan $(32)(n=1)$, Pakistan 


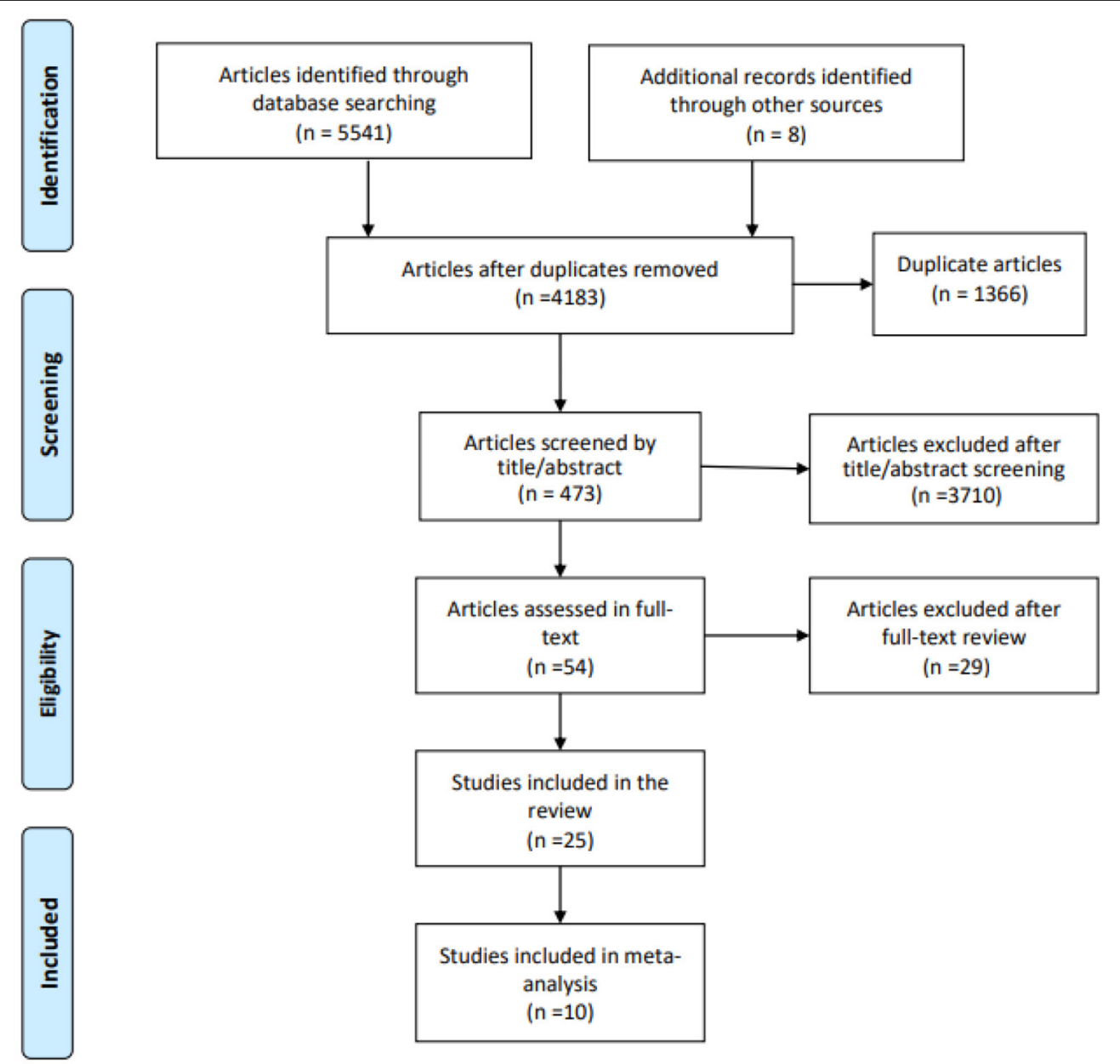

FIGURE 1 | Flowchart of the selected literature.

(25) $(n=1)$, Greece (30) $(n=1)$, Denmark (27) $(n=1)$, and Spain (33) $(n=1)$. All studies were conducted in Asian and European countries, and most of the studies were conducted in developed countries or regions. The majority of the study participants were recruited from the community or from nursing homes. All included studies clearly reported the criteria used for participant enrollment.

The aerobic exercise modalities included in the studies were diverse. There were three dance-based studies $(26,30,32)$, two mixed-modality studies (Tai Chi, treadmill, stationary bike, or other) $(25,29)$, one walking studies $(27)$, one Tai Chi study (28), one aerobic stepping study (31), one cycling study (33), and one handball training study (34). The duration of aerobic exercise interventions was mostly 2-3 times per week for 20$60 \mathrm{~min}$, except for the studies conducted by Lam et al. (28) and Wei et al. (34), which used one and five times, respectively. The intervention duration ranged from 4 months to 1 year, except for one study that used 6 weeks (25). Three of the ten studies compared aerobic exercise with no intervention (i.e., regular physical activity) $(26,27,30)$, three studies compared it with stretching activities $(25,28,29)$, two studies compared it with educational activities $(31,32)$, and two studies compared it with recreational activities $(33,34)$. Even though these studies compared aerobic exercise with stretching activities, educational activities, or recreational activities, these activities were not different from regular physical activity due to their lower level of intensity. They did not change participants' exercise behavior. In the four included studies, during exercise, heart rate was controlled at $40-60 \%(33,34)$ or $60-80 \%$ of the participants' maximum (25) or between 100 and 140 (26) to ensure an aerobic level of intensity was maintained. Other heart rates were described as moderate intensity. Two different cognitive assessment tools, MMSE and MoCA, were used to assess the same cognitive domain within or among studies.

\section{Bias Risk of the Included Studies}

Figure 2 summarizes the risk of bias for the included studies. All included trials used the random assignment method, with seven of them using the method of random number generation of random sequences. However, there were three studies with unclear random assignment methods. The subject selection bias was unclear in five studies, and it was high risk in one study. Only 
TABLE 1 | Characteristics of included trials in this review.

\begin{tabular}{|c|c|c|c|c|c|c|c|c|}
\hline $\begin{array}{l}\text { Author, year } \\
\text { (Ref.) }\end{array}$ & $N(m / f)$ & Age & $\begin{array}{l}\text { Exercise } \\
\text { program }\end{array}$ & Design & $\begin{array}{l}\text { Cognitive } \\
\text { test }\end{array}$ & $\begin{array}{l}\text { Cognitive } \\
\text { domain }\end{array}$ & $\begin{array}{l}\text { Exercise } \\
\text { stimulus }\end{array}$ & $\begin{array}{l}\text { Control } \\
\text { condition }\end{array}$ \\
\hline $\begin{array}{l}\text { Amjad, } 2019 \text { (25) } \\
\text { (Pakistan) }\end{array}$ & 40(21/19) & $\begin{array}{l}\text { CG: } 59.56 \pm \\
2.65 \\
\text { EG: } 58.23 \\
\pm 2.31\end{array}$ & $\begin{array}{l}\text { EG: treadmill, } \\
\text { stationary } \\
\text { bicycle, (aerobic } \\
\text { exercise) } \\
\text { CG: stretch }\end{array}$ & $\mathrm{RCT}$ & $\mathrm{MoCA}$ & $\begin{array}{l}\text { Global cognitive } \\
\text { function }\end{array}$ & $\begin{array}{l}6 \text { weeks, } 3 \\
\text { d/wk, 20-40 } \\
\mathrm{min} / \mathrm{d} \text {, } \\
60-80 \% \text { of } \\
\text { maximum } \\
\text { heart rate }\end{array}$ & Stretch \\
\hline $\begin{array}{l}\text { Hoffmann, } 2015 \\
\text { (27) } \\
\text { (Danmark) }\end{array}$ & $200(113 / 87)$ & $\begin{array}{l}\text { CG: } 71.3 \pm 7.3 \\
\text { EG: } 69.8 \pm 7.4\end{array}$ & $\begin{array}{l}\text { EG: walking } \\
\text { CG: received } \\
\text { treatment as } \\
\text { usual }\end{array}$ & $\mathrm{RCT}$ & MMSE & $\begin{array}{l}\text { Global cognitive } \\
\text { function } \\
\text { Immediate/ } \\
\text { Delayed recall }\end{array}$ & $\begin{array}{l}16 \text { weeks, } 3 \\
\mathrm{~d} / \mathrm{wk}, 60 \mathrm{~min} / \mathrm{d}\end{array}$ & $\begin{array}{l}\text { Received } \\
\text { treatment as } \\
\text { usual }\end{array}$ \\
\hline $\begin{array}{l}\text { Lam, } 2015 \text { (29) } \\
\text { (Hong } \\
\text { Kong, China) }\end{array}$ & 263(54/206) & $\begin{array}{l}\text { CG:75.4 } 46.1 \\
\text { EG: } 76.3 \pm 6.6\end{array}$ & $\begin{array}{l}\text { EG: Tai Chi, } \\
\text { static bicycle } \\
\text { riding and other } \\
\text { physical activity } \\
\text { CG: social } \\
\text { activity }\end{array}$ & $\mathrm{RCT}$ & MMSE & $\begin{array}{l}\text { Global cognitive } \\
\text { function } \\
\text { Delayed recall } \\
\text { Verbal fluency }\end{array}$ & $\begin{array}{l}1 \text { year, } 1 \mathrm{~d} / \mathrm{wk} \text {, } \\
60 \mathrm{~min} / \mathrm{d} \text {, } \\
\text { moderate } \\
\text { intensity }\end{array}$ & $\begin{array}{l}\text { Stretching and } \\
\text { toning exercise }\end{array}$ \\
\hline $\begin{array}{l}\text { Lazarou, } 2017 \text { (30) } \\
\text { (Greece) }\end{array}$ & $129(28 / 101)$ & $\begin{array}{l}\text { CG: } 67.92 \pm 9.47 \\
E G: 65.89 \pm 10.76\end{array}$ & $\begin{array}{l}\text { EG: Dance CG: } \\
\text { usual physical } \\
\text { activity }\end{array}$ & $\mathrm{RCT}$ & MoCA & $\begin{array}{l}\text { Global cognitive } \\
\text { function }\end{array}$ & $\begin{array}{l}10 \text { months, } \\
2 / \mathrm{wk}, 60 \mathrm{~min} / \mathrm{d}\end{array}$ & No intervention \\
\hline $\begin{array}{l}\text { Varela, } 2012 \text { (33) } \\
\text { (Spain) }\end{array}$ & $48(21 / 27)$ & $\begin{array}{l}\text { EG: } \\
77.88 \pm 10.71 \\
\text { CG: } 79.40 \pm 6.72\end{array}$ & $\begin{array}{l}\text { EG: cycling CG: } \\
\text { recreational } \\
\text { activity }\end{array}$ & $\mathrm{RCT}$ & MMSE & $\begin{array}{l}\text { Global cognitive } \\
\text { function }\end{array}$ & $\begin{array}{l}3 \text { months, } 3 \\
\text { d/wk, } 30 \\
\mathrm{~min} / \mathrm{d} \text {, } \\
40-60 \% \\
\text { maximum } \\
\text { heart rate }\end{array}$ & $\begin{array}{l}\text { Recreational } \\
\text { activities } \\
\text { (playing cards, } \\
\text { reading } \\
\text { newspaper) }\end{array}$ \\
\hline $\begin{array}{l}\text { Wei, } 2014 \text { (34) } \\
\text { (China) }\end{array}$ & $60(40 / 20)$ & $\begin{array}{l}C G: 65.27 \pm 4.63 \\
E G: 66.73 \pm 5.48\end{array}$ & $\begin{array}{l}\text { EG: handball } \\
\text { training CG: } \\
\text { entertainment }\end{array}$ & $\mathrm{RCT}$ & MMSE & $\begin{array}{l}\text { Global cognitive } \\
\text { function }\end{array}$ & $\begin{array}{l}6 \text { months, } 5 \\
\text { d/wk,30 } \\
\mathrm{min} / \mathrm{d} \text {, } \\
60 \% \text { Hrmax }\end{array}$ & $\begin{array}{l}\text { Traditional life } \\
\text { entertainment } \\
\text { (playing cards, } \\
\text { etc.) }\end{array}$ \\
\hline
\end{tabular}

one study reported the use of specific allocation concealment through envelope preservation (31). The subject selection bias of five studies was unclear, and for one study, it was high risk. In all included studies, the risk of potential performance bias was high because it was difficult to blind participants to the exercise intervention. Only one cluster-randomized trial was consistent with this potentially performance-biased blinded design (26). All included studies blinded the outcome assessors; therefore, their risk of detection bias was judged as low. The risk of completeness bias for two studies was unclear based on the completeness of the study data or the number of studies describing missing data. The risk of selective reporting bias was judged to be low in five studies 


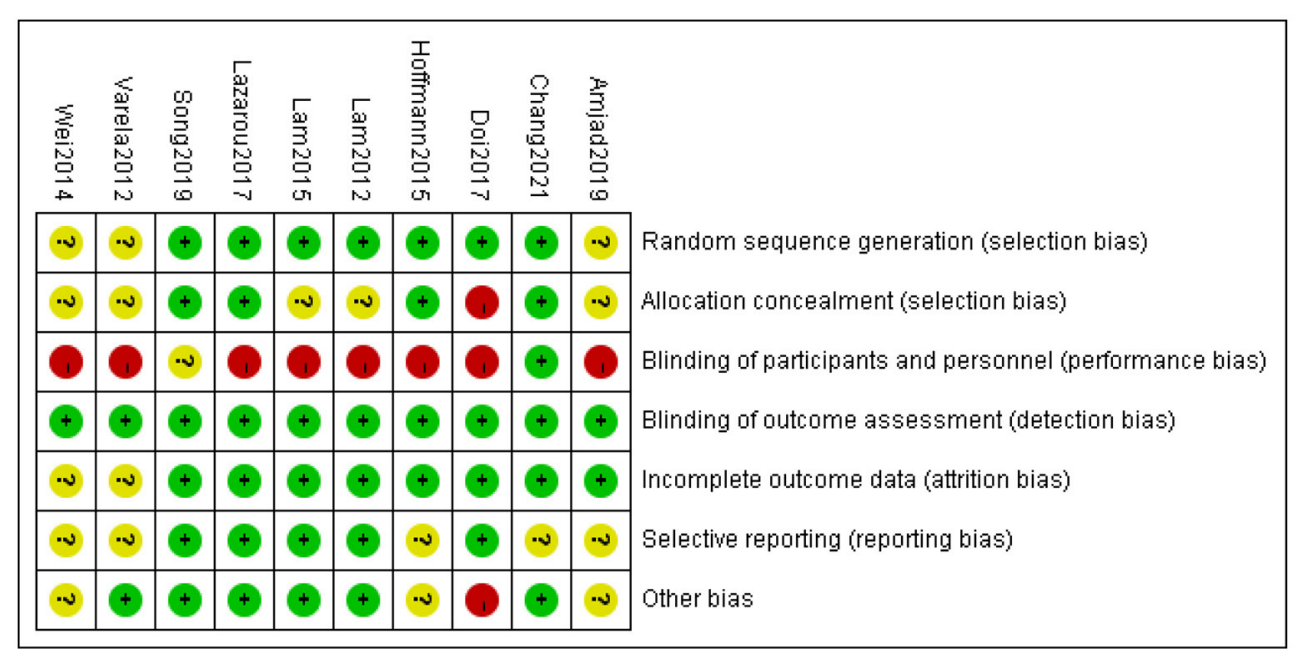

FIGURE 2 | Risk of bias summary of inclusion studies.

after examining the available protocols. The risk of other types of bias was high for one study and unclear for three studies due to their limited sample sizes and unclear comparison with baseline characteristics.

\section{Effect of Intervention}

The effect of aerobic exercise on the overall cognitive performance of MCI patients was tested by assessing cognitive function using the MMSE in six of the ten global impact studies and the MoCA in four studies. The combined analysis of the findings obtained by these two measurement tools was inappropriate due to the inconsistent results between studies that used different measurement tools. Therefore, an analysis of subgroups was required. The results of the subgroup analysis showed that aerobic exercise significantly improves the overall cognitive performance of patients with MCI as shown by significant improvements in MMSE $(N=956, M D=0.60$, 95\% CI: $0.28-0.92, p=0.0003, I^{2}=31 \%$, fixed-effects model) and MoCA scores $(N=398, M D=1.67,95 \% \mathrm{CI}: 1.18-2.15, p$ $<0.0001, I^{2}=37 \%$ ), significantly improved overall cognitive performance in patients with MCI (Figure 3).

\section{DISCUSSION}

This systematic review and meta-analysis provides positive evidence that aerobic exercise significantly improves cognitive performance in older adults with MCI.

None of the included studies reported adverse events related to aerobic exercise. However, the results of some other studies are inconsistent with ours. The use of different trial periods may have led to inconsistency in results. For example, some reports showed no difference between the experimental and control groups in the area of overall cognitive function following a 3month intervention (35). In contrast, other trials with longer intervention or follow-up periods identified an improvement in cognitive function $(29,30,32,36)$. In addition, a study using the MoCA measurement tool found no significant improvement after 3 months of intervention (36), while another study showed significant effects after a 10-month intervention (30). Only four of the included studies specified aerobic exercise intensity with target peak levels of $40-60 \%, 60-80 \%, 60 \%$, and a heart rate maintained at $100-140$ beats per minute $(25,26,33,34)$. This indicates that exercise intensity may be a factor associated with inconsistent results.

A review study proposed that location and gender may affect the impact of an intervention. In this study, three studies were conducted in mainland China, two studies were from Hong Kong, China, and the remaining studies were conducted in Japan, Pakistan, Denmark, Spain, and Greece. Geographically, six studies were conducted in East Asia (26, 28, 29, 31, 32, 34) and four were conducted in Europe and South Asia (25, 27, 30, 33). Geographical concentration may influence the effect of an intervention. In addition, the influence of the gender factor is mainly reflected in the balanced distribution of subjects. For example, in Chang et al.'s study $(26,37)$, all participants were female, so their study design excluded the interference of gender factors in the experiment. In contrast, in the study designs of Lam et al. (28) and Lazarous et al. (30), the proportion of females was more than $75 \%$, which implies a three-to-one gap.

\section{STRENGTHS AND LIMITATIONS}

The strength of this review lies in its systematic approach design. The strength of our design is reflected in three main areas. First, we focused on aerobic exercise. By defining the concept of aerobic exercise, the use of moderate-intensity exercise was identified as an inclusion criterion. In addition, the selection of exercise programs for MCI patients included tai chi, qigong, dance (square dance), yoga, running, walking, and stepping. Second, we focused on the use of measurement tools. Only trials measured by two instruments, MMSE and MoCA, were 


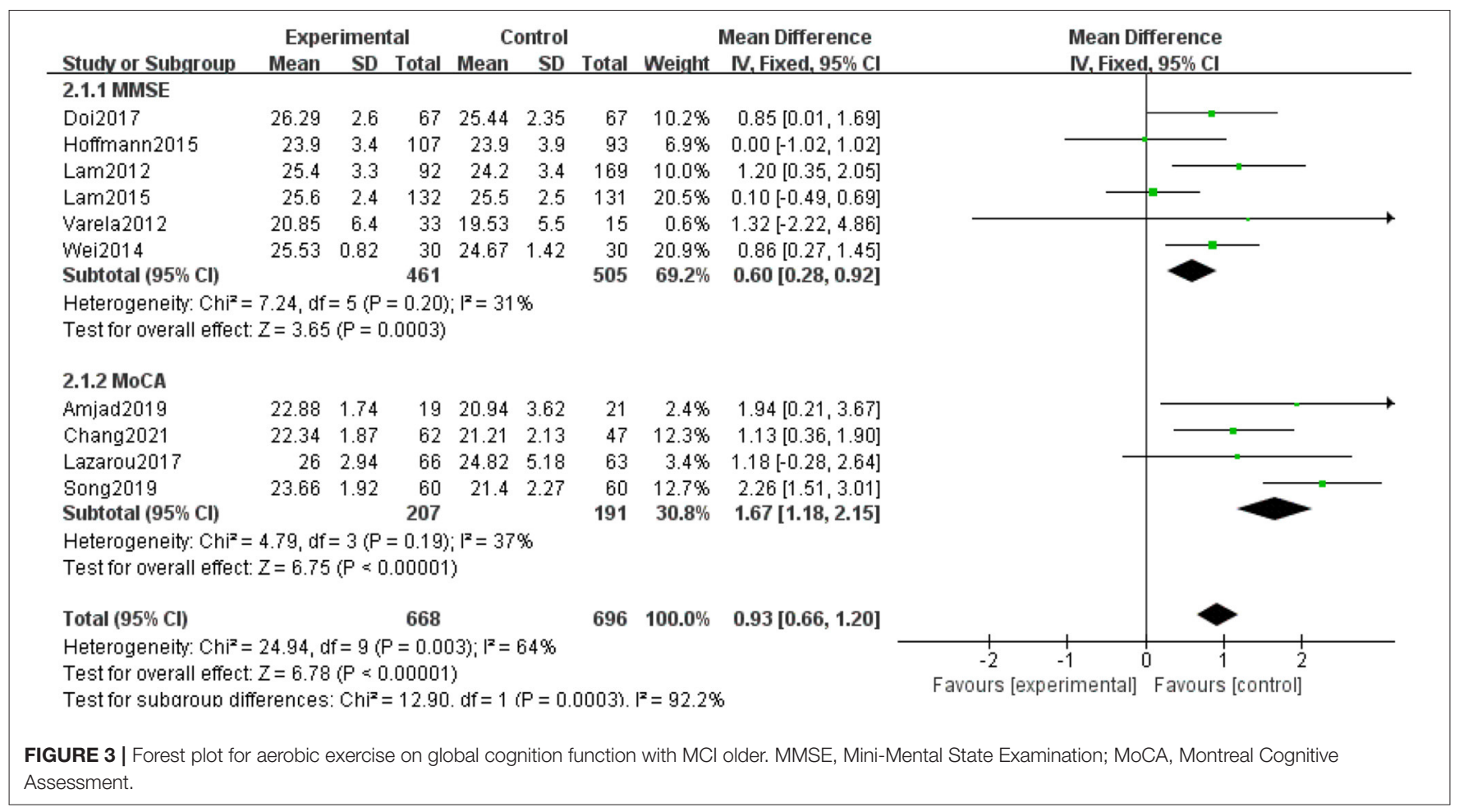

included in the study. This was done to allow us to validate the consistency of the results and to prevent the inclusion of multiple measurement tools from affecting the validity of the analysis. Third, we only discussed the effects of aerobic exercise on global cognitive function in MCI patients and not on specific domains of cognitive function. This allowed us to focus more on the effects of the intervention and thus identify whether aerobic exercise can affect the cognitive performance of patients with MCI.

This study has several limitations. First, the types of aerobic exercise included in the study were diverse, and it is uncertain whether consistent effects were observed due to the different exercise programs used. Second, the frequency and intensity of exercise varied among studies, and the resulting mechanisms of exercise are unclear. Third, although the two measurement tools used have high reliability and validity, their objective measurements need to be further enhanced, for example, through the use of EEG or MRI. Fourth, the standardization of RCTs still needs to be improved. Fifth, insufficient sample size may have seriously limited the interpretability of the results, with three of the 10 studies having sample sizes of $<100$ individuals. In conclusion, the results of this study confirm the positive effect of aerobic exercise as an intervention for MCI patients. However, the above deficiencies remind us that the effect values provided by the meta-analysis should be interpreted with caution.

\section{CONCLUSION}

Participation in aerobic exercise can contribute to the improvement of overall cognitive function in elderly MCI patients. However, the mechanisms by which aerobic exercise influences the overall cognition of MCI patients are unclear due to differences in the type, frequency, and duration of aerobic exercise used in previous studies. Largescale, rigorous RCTs are needed to explore specific areas of impact and mechanisms of action and determine appropriate intervention programs.

\section{DATA AVAILABILITY STATEMENT}

The raw data supporting the conclusions of this article will be made available by the authors, without undue reservation.

\section{AUTHOR CONTRIBUTIONS}

LY, GY, and HS: data collection. LY, LL, TD, JC, and MY: data analysis, conception, and design. LY, JW, JC, and MY: research design, writing the manuscript, and revision. All authors contributed to the article and approved the submitted version.

\section{FUNDING}

This study was supported by the Graduate Students Innovation Program of Chongqing (CYS21086), the Fundamental Research Funds for the Central Universities of Southwest University (SWU1709240), the Medical Research Program Project of Chongqing Municipal Health and Family Planning Commission 
(2015ZDXM034), and the Fundamental Research Funds for the Central Universities of Tongji University (22120180511).

\section{ACKNOWLEDGMENTS}

We sincerely appreciate all the contributors included in the research literature. This study would not have been possible without your research. In addition, we

\section{REFERENCES}

1. Petersen RC. Mild cognitive impairment as a diagnostic entity. J Intern Med. (2004) 256:183-94. doi: 10.1111/j.1365-2796.2004.01388.x

2. Hu C, Yu D, Sun X, Zhang M, Wang L, Qin H. The prevalence and progression of mild cognitive impairment among clinic and community populations: a systematic review and meta-analysis. Int Psychogeriatr. (2017) 29:1595. doi: 10.1017/S1041610217000473

3. Xue J, Li J, Liang J, Chen S. The prevalence of mild cognitive impairment in China: a systematic review. Aging Dis. (2018) 9:706. doi: 10.14336/AD.2017.0928

4. Hao L, Wang X, Zhang L, Xing Y, Guo Q, Hu X, et al. Prevalence, risk factors, and complaints screening tool exploration of subjective cognitive decline in a large cohort of the Chinese population. J Alzheimers Dis. (2017) 60:371-88. doi: 10.3233/JAD-170347

5. Feldman HH, Ferris S, Winblad B, Sfikas N, Mancione L, He Y, et al. Effect of rivastigmine on delay to diagnosis of Alzheimer's disease from mild cognitive impairment: the InDDEx study. Lancet Neurol. (2007) 6:50112. doi: 10.1016/S1474-4422(07)70109-6

6. Cooper C, Li R, Lyketsos C, Livingston G. Treatment for mild cognitive impairment: systematic review. Br J Psychiatry. (2013) 20:255-64. doi: 10.1192/bjp.bp.113.127811

7. Langa KM, Levine DA. The diagnosis and management of mild cognitive impairment: a clinical review. JAMA. (2014) 312:2551-61. doi: 10.1001/jama.2014.13806

8. Tricco AC, Soobiah C, Berliner S, Ho JM, Ng CH, Ashoor HM, et al. Efficacy and safety of cognitive enhancers for patients with mild cognitive impairment: a systematic review and meta-analysis. CMAJ. (2013) 185:1393401. doi: 10.1503/cmaj.130451

9. Eshkoor SA, Hamid TA, Mun CY, Ng CK. Mild cognitive impairment and its management in older people. Clin Interv Aging. (2015)10:687. doi: 10.2147/CIA.S73922

10. Roberts RO, Geda YE, Cerhan JR, Knopman DS, Cha RH, Christianson TJ, et al. Vegetables, unsaturated fats, moderate alcohol intake, and mild cognitive impairment. Dement Geriatr Cogn Disord. (2010) 29:41323. doi: 10.1159/000305099

11. Horr T, Messinger-Rapport B, Pillai JA. Systematic review of strengths and limitations of randomized controlled trials for non-pharmacological interventions in mild cognitive impairment: focus on Alzheimer's disease. $J$ Nutr Health Aging. (2015) 19:141-53. doi: 10.1007/s12603-014-0565-6

12. Jeong Hong Y, Hye Jang E, Hwang J, Hoon Roh J, Lee JH. The efficacy of cognitive intervention programs for mild cognitive impairment: a systematic review. Curr Alzheimer Res. (2015) 12:527-42. doi: 10.2174/1567205012666150530201636

13. Sherman DS, Mauser J, Nuno M, Sherzai D. The efficacy of cognitive intervention in mild cognitive impairment (MCI): a meta-analysis of outcomes on neuropsychological measures. Neuropsychol Rev. (2017) 27:44084. doi: 10.1007/s11065-017-9363-3

14. Gates NJ, Sachdev PS, Singh MA, Valenzuela M. Cognitive and memory training in adults at risk of dementia: a systematic review. BMC Geriatr. (2011) 11:1-4. doi: 10.1186/1471-2318-11-55

15. Zheng G, Xia R, Zhou W, Tao J, Chen L. Aerobic exercise ameliorates cognitive function in older adults with mild cognitive impairment: a systematic review and meta-analysis of randomised controlled trials. Br J Sports Med. (2016) 50:1443-50. doi: 10.1136/bjsports-2015-095699 would like to thank the reviewers for their comments and suggestions.

\section{SUPPLEMENTARY MATERIAL}

The Supplementary Material for this article can be found online at: https://www.frontiersin.org/articles/10.3389/fpsyt. 2021.713671/full\#supplementary-material

16. Ströhle A, Schmidt DK, Schultz F, Fricke N, Staden T, Hellweg R, et al. Drug and exercise treatment of Alzheimer disease and mild cognitive impairment: a systematic review and meta-analysis of effects on cognition in randomized controlled trials. Am J Geriatr Psychiatry. (2015) 23:123449. doi: 10.1016/j.jagp.2015.07.007

17. Vega JN, Newhouse PA. Mild cognitive impairment: diagnosis, longitudinal course, and emerging treatments. Curr Psychiatry Rep. (2014) 16:490. doi: 10.1007/s11920-014-0490-8

18. Cui MY, Lin Y, Sheng JY, Zhang X, Cui RJ. Exercise intervention associated with cognitive improvement in Alzheimer's disease. Neural Plast. (2018). 9234105. doi: 10.1155/2018/9234105

19. Hahn EA, Andel R. Nonpharmacological therapies for behavioral and cognitive symptoms of mild cognitive impairment. J Aging Health. (2011) 23:1223-45. doi: 10.1177/0898264311422745

20. Teixeira CV, Gobbi LT, Corazza DI, Stella F, Costa JL, Gobbi S. Nonpharmacological interventions on cognitive functions in older people with mild cognitive impairment (MCI). Arch Gerontol Geriatr. (2012) 54:17580. doi: 10.1016/j.archger

21. Gallaway PJ, Miyake H, Buchowski MS, Shimada M, Yoshitake Y, Kim AS, et al. Physical activity: a viable way to reduce the risks of mild cognitive impairment, Alzheimer's disease, and vascular dementia in older adults. Brain Sci. (2017) 7:22. doi: 10.3390/brainsci7020022

22. Moher D, Liberati A, Tetzlaff J, Altman DG; PRISMA Group. Preferred reporting items for systematic reviews and metaanalyses: the PRISMA statement. Ann Intern Med. (2009)151:2649. doi: 10.7326/0003-4819-151-4-200908180-00135

23. Higgins JP, Thomas J, Chandler J, Cumpston M, Li T, Page MJ, et al., editors. Cochrane Handbook for Systematic Reviews of Interventions. Chichester: John Wiley and Sons (2019).

24. Higgins JP, Thompson SG, Deeks JJ, Altman DG. Measuring inconsistency in meta-analyses. BMJ. (2003) 327:557-60. doi: 10.1136/bmj.327.7414.557

25. Amjad I, Toor H, Niazi IK, Afzal H, Jochumsen M, Shafique M, et al. Therapeutic effects of aerobic exercise on EEG parameters and higher cognitive functions in mild cognitive impairment patients. Int $J$ Neurosci. (2019) 129:551-62. doi: 10.1080/00207454.2018.1551894

26. Chang J, Chen Y, Liu C, Yong L, Yang M, Zhu W, et al. Effect of square dance exercise on older women with mild mental disorders. Front Psychiatry. (2021) 12:699778. doi: 10.3389/fpsyt.2021.699778

27. Hoffmann K, Sobol NA, Frederiksen KS, Beyer N, Vogel A, Vestergaard K, et al. Moderate-to-high intensity physical exercise in patients with Alzheimer's disease: a randomized controlled trial. J Alzheimers Dis. (2016) 50:44353. doi: 10.3233/JAD-150817

28. Lam LC, Chau RC, Wong BM, Fung AW, Tam CW, Leung GT, et al. A 1year randomized controlled trial comparing mind body exercise (Tai Chi) with stretching and toning exercise on cognitive function in older Chinese adults at risk of cognitive decline. J Am Med Dir Assoc. (2012) 13:568.e1520. doi: 10.1016/j.jamda.2012.03.008

29. Lam LC, Chan WC, Leung T, Fung AW. Leung EM. Would older adults with mild cognitive impairment adhere to and benefit from a structured lifestyle activity intervention to enhance cognition?: a cluster randomized controlled trial. PLoS ONE. (2015) 31:e0118173. doi: 10.1371/journal.pone.0118173

30. Lazarou I, Parastatidis T, Tsolaki A, Gkioka M, Karakostas A, Douka S, Tsolaki M. International ballroom dancing against neurodegeneration: a randomized controlled trial in Greek communitydwelling elders with mild cognitive impairment. Am J Alzheimers 
Dis Other Demen. (2017) 32:489-99. doi: 10.1177/15333175177 25813

31. Song D, Doris SF. Effects of a moderate-intensity aerobic exercise programme on the cognitive function and quality of life of community-dwelling elderly people with mild cognitive impairment: a randomised controlled trial. Int J Nurs Stud. (2019) 93:97-105. doi: 10.1016/j.ijnurstu

32. Doi T, Verghese J, Makizako H, Tsutsumimoto K, Hotta R, Nakakubo S, et al. Effects of cognitive leisure activity on cognition in mild cognitive impairment: results of a randomized controlled trial. J Am Med Dir Assoc. (2017) 18:686-91. doi: 10.1016/j.jamda.2017.02.013

33. Varela S, Ayán C, Cancela JM, Martín V. Effects of two different intensities of aerobic exercise on elderly people with mild cognitive impairment: a randomized pilot study. Clin Rehabil. (2012)26:442-50. doi: 10.1177/0269215511425835

34. Wei XH Ji LL. Effect of handball training on cognitive ability in elderly with mild cognitive impairment. Neurosci Lett. (2014) 566:98101. doi: 10.1016/j.neulet

35. Barnes DE, Santos-Modesitt W, Poelke G, Kramer AF, Castro C, Middleton LE, et al. The Mental Activity and eXercise (MAX) trial: a randomized controlled trial to enhance cognitive function in older adults. JAMA Intern Med. (2013) 173:797-804. doi: 10.1001/jamainternmed.2013.189
36. Zhu Y, Wu H, Qi M, Wang S, Zhang Q, Zhou L, et al. Effects of a specially designed aerobic dance routine on mild cognitive impairment. Clin Interv Aging. (2018) 13:1691. doi: 10.2147/CIA.S 163067

37. Chang J, Zhu W, Zhang J, Yong L, Yang M, Wang J, et al. The effect of Chinese square dance exercise on cognitive function in older women with mild cognitive impairment: the mediating effect of mood status and quality of life. Front Psychiatry. (2021) 12:711079. doi: 10.3389/fpsyt.2021. 711079

Conflict of Interest: The authors declare that the research was conducted in the absence of any commercial or financial relationships that could be construed as a potential conflict of interest.

Copyright (c) 2021 Yong, Liu, Ding, Yang, Su, Wang, Yang and Chang. This is an open-access article distributed under the terms of the Creative Commons Attribution License (CC BY). The use, distribution or reproduction in other forums is permitted, provided the original author(s) and the copyright owner(s) are credited and that the original publication in this journal is cited, in accordance with accepted academic practice. No use, distribution or reproduction is permitted which does not comply with these terms. 